Article

\title{
Pre-Inscribed Laser Surface Pattering for Increased Joining Strength in Laser Fusion Bonding of CFRP and Zinc-Coated Steel
}

\author{
Dong-Hyuck Kam ${ }^{1}{ }^{\mathbb{D}}$, Nam-Ki Jeon ${ }^{1,2}$, Taek-Eon Jeong ${ }^{1,2}$ and Jedo Kim ${ }^{3, *}$ \\ 1 Joining R\&D Group, Korea Institute of Industrial Technology, Incheon 21999, Korea; \\ kamdong@kitech.re.kr (D.-H.K.); namgijeon@kitech.re.kr (N.-K.J.); taekeonjeon@kitech.re.kr (T.-E.J.) \\ 2 Department of Mechanical Convergence Engineering, Hanyang University, Seoul 04763, Korea \\ 3 Department of Mechanical and Systems Design Engineering, Hongik University, Seoul 04066, Korea \\ * Correspondence: jedokim@hongik.ac.kr
}

Received: 5 October 2019; Accepted: 28 October 2019; Published: 31 October 2019

\begin{abstract}
In this study, we present improved fusion-bonding strength results between carbon fiber-reinforced polyetheretherketone (CFR-PEEK) and zinc-coated steel through the introduction of pre-inscribed laser surface patterns. Optimized laser welding parameters, including laser power, focal position, pitch, number of passes, and clamping pressure, are presented along with parameters for producing the rectangular laser patterns. It was found that for the optimized parameters, the tensile shear strength of the welded samples is improved by as much as $100 \%$ when pre-inscribed laser patterns are present. Detailed SEM images of the fractured fusion welded joint samples after the tensile shear test are presented for analysis. The tight bonding between the polymer matrix and the zinc-coated steel inside the formed grooves is found to be the main reason behind the increased tensile shear strength. A comparison of the tensile shear loads for various joining methods is also presented and discussed.
\end{abstract}

Keywords: CRFP and metal joint; dissimilar joining; laser fusion welding; zinc-coated steel; laser surface patterning

\section{Introduction}

Carbon fiber-reinforced plastic (CFRP) is an attractive material candidate for weight reduction due to its high strength-to-weight ratio compared to metals. It is especially promising for the automotive industry since toughening environmental regulations and high fuel prices have demanded reduced carbon emissions and improved fuel efficiency [1-3]. However, the lack of reliable and productive means for joining dissimilar materials has limited the use of CFRPs. Only a handful of methods for joining CFRP and other metals have been used such as chemical binders and a few mechanical means. The toxic chemicals comprising the binders pose serious environmental and health problems and the relatively long processing time accompanied by the need for temporary fixtures has made chemical joining process inefficient [1]. The mechanical joining methods usually require careful alignment of the holes between the parts to be joined, and this poses a challenge for automation. In addition, the added weight of rivets, bolts, and screws increases the overall weight, which defeats the purpose of using lightweight CFRPs [1]. Furthermore, at the end of the lifecycle of the products, the presence of both chemical binders and mechanical joints makes recycling costly, which can be a significant environmental issue in the near future. Therefore, there is a high demand for new joining technologies such as fusion welding. Fusion welding is nearly impossible for thermoset CFRPs since they burn under the intense heat of the welding process. Thermoplastic CFRPs, on the other hand, allow fusion welding and thus can be a good alternative for increasing the production efficiency [4-7]. Thermoplastic 
CFRP has been known to exhibit lower strength and lower heat resistance compared to its thermoset counterpart, but the recent advancement of thermoplastics has removed most of its weaknesses [8].

Many prior studies have investigated the application of laser fusion welding between CFRP and metals [4-7]. Katayama et al. [4,5] showed that tight bonding between the polymer matrix and the metal surface could be achieved by generating bubbles in the molten zone of the CFRP matrix. Expanding pressure caused by the bubbles pushes the molten polymer flow onto the metal surface structures. Surface pre-treatments prior to the joining process have been demonstrated as an effective method to enhance dissimilar joining strength [6,7]. Lambiase and Ko investigated the feasibility of mechanical clinching for CFRP-aluminum joining and found that a high jointing strength of $2.5 \mathrm{kN}$ can be achieved. Zhang et al. [9] showed that the pre-treatment of aluminum with the laser Surfi-Sculpt process could improve the shear strength of dissimilar joints to a large extent and discussed the bonding and the failure mechanisms of the dissimilar joints. The same group also investigated the effect of surface grafting on the laser joining strength of CFRP and aluminum alloy [10]. The results showed that the shear strength of the joint could be enhanced up to $600 \%$ using optimized UV grafting parameters, and new bonds including $\mathrm{Al}-\mathrm{C}$ and $\mathrm{Al}-\mathrm{O}-\mathrm{C}$ could be the reason for such high joining strength improvement [11].

In this study, we investigate the influence of pre-inscribed laser surface patterning, via nanosecond pulse laser, on the laser fusion-bonding strength of carbon fiber-reinforced polyetheretherketone (CFR-PEEK) and zinc-coated steel (so-called galvannealed steel). The materials are chosen since PEEK is considered as one of the most promising candidates for replacing PA6 or PA66 for a thermoplastic polymer matrix for carbon fiber composites due to its high thermal resistance, mechanical strength, and moisture resistance, and zinc-coated steel has been increasingly adopted in the automotive industry for improved corrosion resistance [8]. Optimization of the processing parameters, including laser power, focal position, pitch, number of passes, and clamping pressure was done prior to introducing the pre-inscribed laser patterns. Then, the laser power, a number of passes, and pitch were varied to find the optimized patterning parameters using the secondary nanosecond laser. The tensile shear strength test reveals that the strength of the joint with laser surface structuring increased by up to $100 \%$ compared to that of the samples without surface structures. We also present SEM images of the patterned surface and the cross-section of the joint to investigate the nature of the increased bonding strength and the optimized parameters.

\section{Materials and Methods}

The schematic of the laser fusion bonding (or welding) of CFRP and zinc-coated steel is shown in Figure 1. Commercially available 1.6-mm thick tri-axial $\left(0^{\circ} /-60^{\circ} /+60^{\circ}\right)$ non-crimp fabric with tricot counter-stitch and a polyetheretherketone (PEEK) matrix was used for the CFRP sample (manufacturer: SAERTEX ${ }^{\circledR}$ GmbH \& Co., Saerbeck, Germany, KG), while 2.6-mm thick commercially available zinc-coated DP 590 steel sheets with $43.8 \mathrm{~g} / \mathrm{m}^{2}$ of zinc coating applied on each side were used as the joining counterpart. The roughness was measured using a surface profiler (Mitutoyo SJ-400), and the values for the CFRP and the steel sheets were $\mathrm{Ra}=0.29 \mu \mathrm{m}, \mathrm{Ry}=2.53 \mu \mathrm{m}$ and $\mathrm{Ra}=1.21 \mu \mathrm{m}$, Ry $=8.83 \mu \mathrm{m}$, respectively. A continuous mode Yb:YAG disk laser HLD 4002 (Trumpf, Ditzingen, Germany) was used for the laser welding process. The laser beam was delivered through an optical fiber with a diameter of $200 \mu \mathrm{m}$ and optic system PFO33 (Trumpf, Ditzingen, Germany). The delivered beam was collimated (length of collimation: $150 \mathrm{~mm}$ ) and focused (focal length: $450 \mathrm{~mm}$ ), which resulted in a focal diameter of $0.6 \mathrm{~mm}$ with a beam quality (beam parameter product) of $8.5 \mathrm{~mm} \cdot \mathrm{rad}$. The welding was done on a custom-made jig (shown in the bottom of Figure 1) with a clamping pressure of $P_{c}$. No shielding gas was used in this study. 
(a)

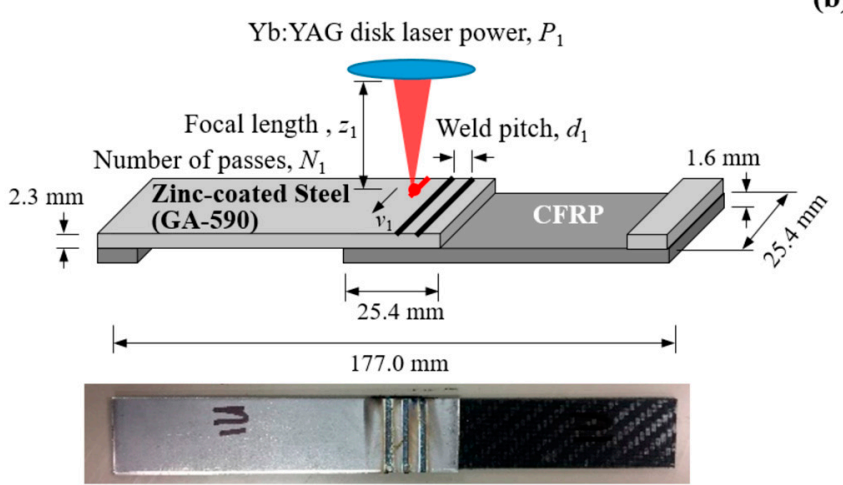

(b)

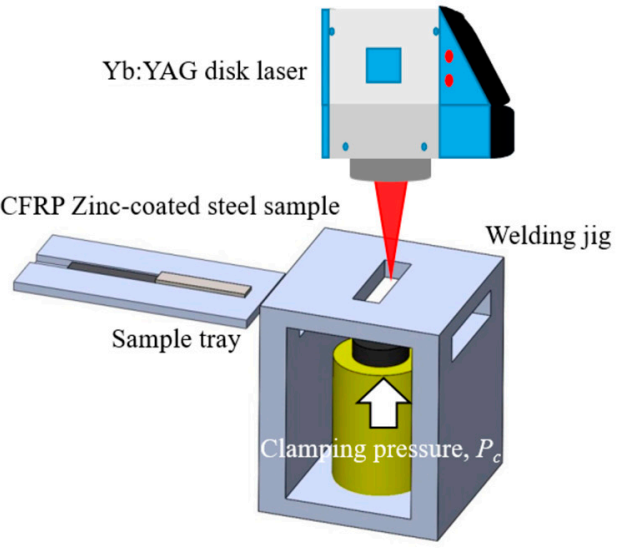

Figure 1. (a) Schematic diagram of the laser fusion welding of carbon fiber-reinforced plastic (CFRP) and zinc-coated steel and the welded sample. The laser fusion welding was done using a laser with a power of $P_{1}$, a focal length of $z_{1}$, and the number of passes as $N_{1}$. (b) The custom-made jig design is also shown as a $3 \mathrm{D}$ rendering in which the samples are placed for the laser fusion welding process.

The rectangular laser pattern on the zinc-coated steel surface was produced using a nanosecond pulsed fiber laser (IPG YLPN-1-20 × 120-100) operating at $1064 \mathrm{~nm}$. The laser was set to produce 120-ns pulses at a frequency of $50 \mathrm{kHz}$. The average output power was varied between 8 and $45 \mathrm{~W}$. The beam shape was near-Gaussian, and at focus, the beam spot size of full width 1/e2 maximum (FW1/e2M) was approximately $125 \mu \mathrm{m}$ in diameter. A two-mirrored galvanometric scanner and an $\mathrm{X}-\mathrm{Y}-\mathrm{Z}$ motion stage were used to control the position and the motion of the laser beam spots for the production of the rectangular grid pattern shown in Figure 2.
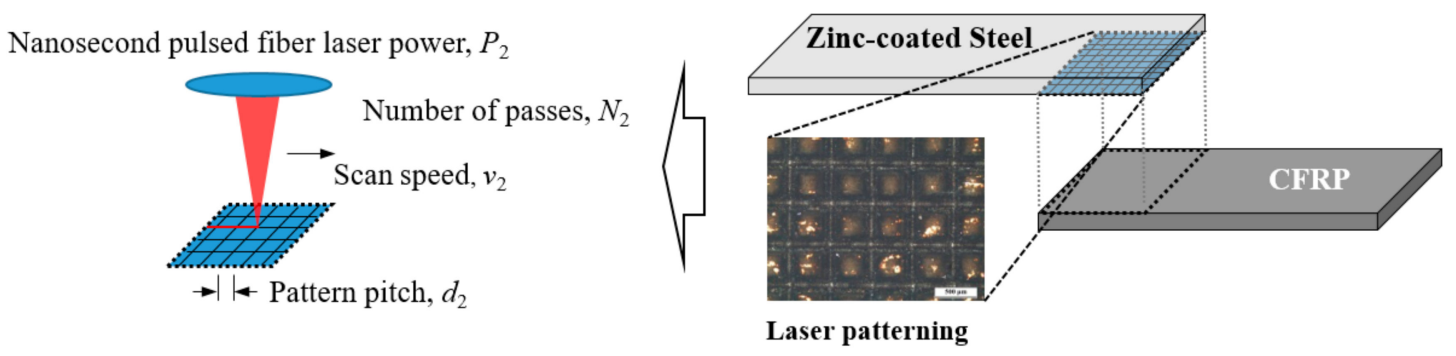

Figure 2. Schematic of the laser surface pattered zinc-coated steel using a nanosecond pulsed fiber laser. The pre-inscribed rectangular pattern is formed by irradiation of a laser with a power of $P_{2}$, the number of passes as $N_{2}$, and a scan speed of $v_{2}$.

The tensile shear tests, to quantify the joining strength of the laser-welded samples, were performed using a Shimadzu AG-300KNX Universal Testing Machine (maximum load capacity of 30 tons). The dimensions of the specimen and the test procedure conform to the ASTM D 5868 standard, and the schematic of the tensile test specimen is shown in Figure 1. Three samples for each condition were prepared, and the results were averaged. The crosshead speed was $5 \mathrm{~mm} / \mathrm{min}$ for all the tensile shear tests.

\section{Results and Discussion}

To find the optimal processing conditions for the laser fusion bonding of CFRP and zinc-coated steel, a parametric study was performed by varying the welding parameters, and the tensile shear load test results of each case are shown in Figure 3. Figure 3a shows the tensile shear load with respect to (w.r.t.) the laser power $P_{1}$ at different focal positions, $z_{1}=5,10,15 \mathrm{~mm}$. The figure shows that for the samples used in this study, the optimal laser power is approximately $0.7 \mathrm{~kW}$, resulting in a tensile shear load of $4.26 \mathrm{kN}$ at $z_{1}=10 \mathrm{~mm}$. The optimal laser power was chosen since the results show high tensile 
shear load test results for all the focal lengths with a minimum amount of errors. The figure also shows that the optimal $z_{1}$ value is $10 \mathrm{~mm}$, which results in a relatively high tensile shear load with relatively small variations. Next, the influence of the pitch $d_{1}$ on the tensile shear load is investigated, and the results are presented in Figure $3 \mathrm{~b}$. The figure shows that the maximum tensile shear load of $4.26 \mathrm{kN}$ is obtained for the weld pitch of $d_{1}=5 \mathrm{~mm}$. The results show that as $d_{1}$ is increased from 1 to $5 \mathrm{~mm}$, the tensile shear load is increased. However, when $d_{1}$ is increased above $5 \mathrm{~mm}$, the results become unreliable, although the maximum tensile load is maintained at approximately $4.2 \mathrm{kN}$. The number of passes $N_{1}$ in each weld line is found to be an important parameter, and the tensile load test results w.r.t. $N_{1}$ are shown in Figure 3c. The results in the figure show that the tensile shear load of $N_{1}=2$ is significantly higher than that of $N_{1}=1$, since a single path is not enough to fully fuse the two materials at the optimized laser power of $0.7 \mathrm{~kW}$. However, as $N_{1}$ is increased beyond 2, the tensile shear strength is decreased, which is suspected to be the result of the increased thermal damage on the polymer matrix of the CFRP in the interfacial area. Finally, tensile shear load tests, for the samples using different clamping pressures denoted by $P_{c}$ are conducted, and the results are shown in Figure $3 \mathrm{~d}$. The figure shows that the tensile shear load is maintained at approximately $4 \mathrm{kN}$ up to $P_{c}=5 \mathrm{MPa}$. However, the reliability is reduced as it is further increased.

(a)

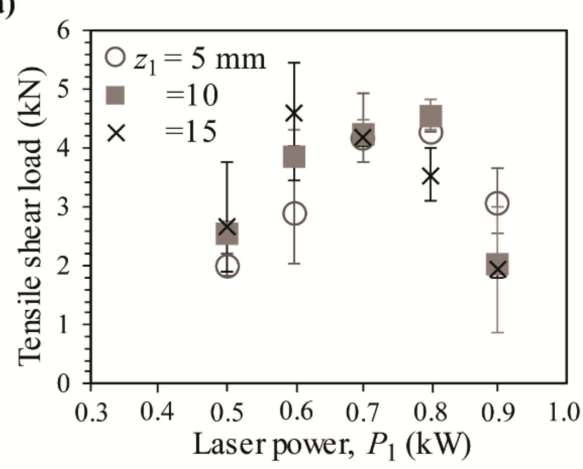

(c)

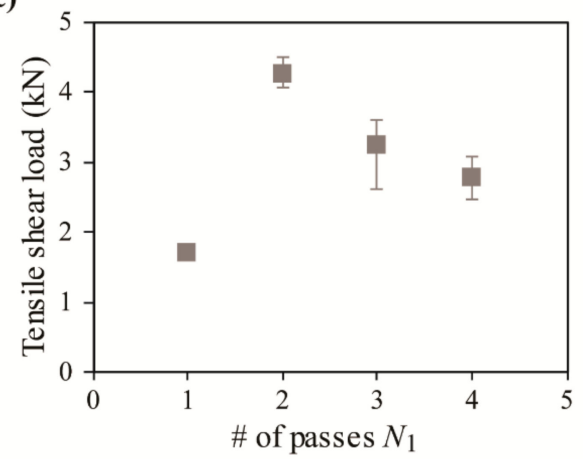

(b)

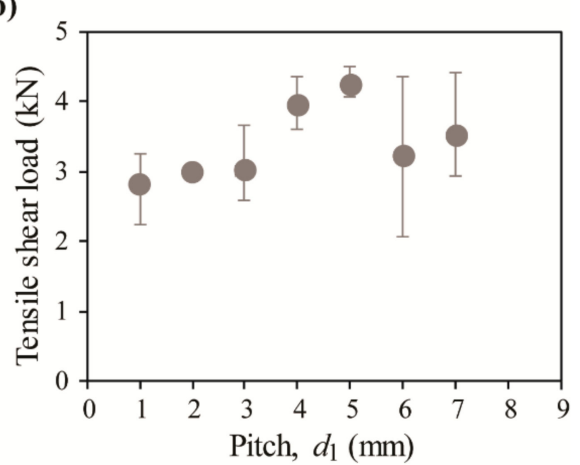

(d)

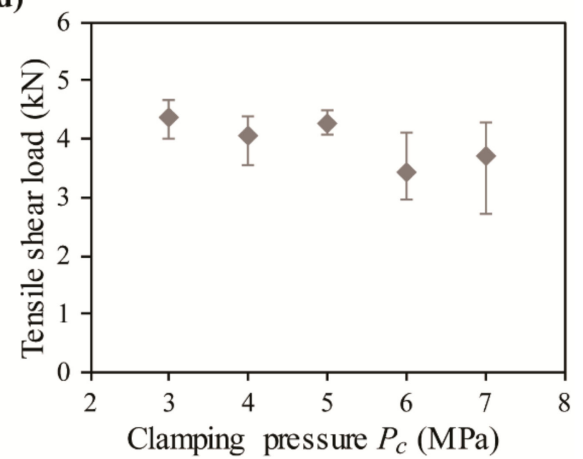

Figure 3. (a) Tensile shear load variation with respect to (w.r.t.) laser power, $P_{1}$ for laser focal positions $z_{1}=5,10,15 \mathrm{~mm} . d_{1}=5 \mathrm{~mm}, N_{1}=2, P_{c}=5 \mathrm{MPa}$, and $v_{1}=10 \mathrm{~mm} / \mathrm{min}$ were used. (b) Tensile shear load variation w.r.t. the weld pitch, $d_{1} . P_{1}=0.7 \mathrm{~kW}, z_{1}=10 \mathrm{~mm}, N_{1}=2, P_{c}=5 \mathrm{MPa}$, and $v_{1}=10 \mathrm{~mm} / \mathrm{min}$ were used. (c) Tensile shear load variation w.r.t. the number of passes $N_{1} . P_{1}=0.7 \mathrm{~kW}, z_{1}=10 \mathrm{~mm}$, $d_{1}=3 \mathrm{~mm}, P_{c}=5 \mathrm{MPa}$, and $v_{1}=10 \mathrm{~mm} / \mathrm{min}$ were used. (d) Tensile shear load variation w.r.t. the clamping pressure $P_{c} . P_{1}=0.7 \mathrm{~kW}, z_{1}=10 \mathrm{~mm}, d_{1}=5 \mathrm{~mm}, N_{1}=2$, and $v_{1}=10 \mathrm{~mm} / \mathrm{min}$ were used.

The parametric study shows that for this study, the optimized laser processing parameters in laser fusion welding of CFRP and zinc-coated steel are: $P_{1}=0.7 \mathrm{~kW}, z_{1}=10 \mathrm{~mm}, d_{1}=3 \mathrm{~mm}, N_{1}=2$, and $P_{c}=5 \mathrm{MPa}$. We use these parameters for investigating the effect of pre-inscribed rectangular patterns on the joining strength of the two dissimilar materials. 
In an effort to increase the bonding strength of the fusion welded joint between CFRP and the zinc-coated steel sheets, the surface of the steel, which overlaps with the CFRP sample, is pre-inscribed with a rectangular pattern using a nanosecond pulsed laser, as shown in Figure 4a. The laser pattern chosen for this study is a rectangular pattern with a varying line pitch represented by $d_{2}$, as shown in Figure $4 \mathrm{~b}$. The magnified image in Figure $4 \mathrm{c}$ shows that when the surface of the steel is patterned using the nanosecond laser, the recondensed debris from the process forms a hump along the laser path. Figure $4 \mathrm{~d}$ shows the SEM image of the laser patters as $N_{2}$ is increased from 1 to 5 . It shows that although the depth of the pattern consistently increases as $N_{2}$ is increased, the width of the pattern is not consistent, yet decreases due to the increased amount of recondensed debris after $N_{2}=3$.
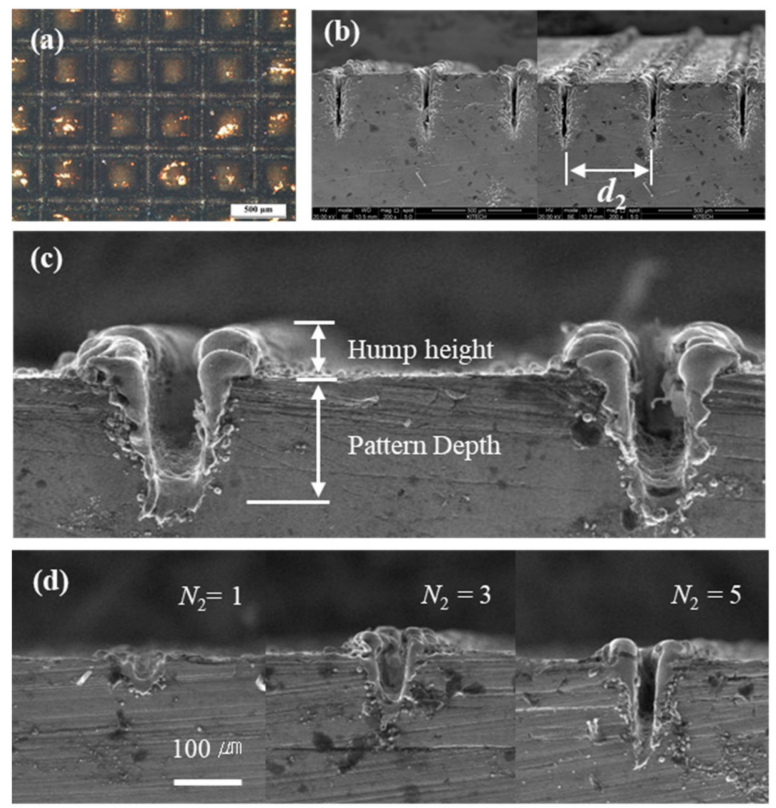

Figure 4. (a) The rectangular grid pattern of the laser patterning on the zinc-coated steel surface with $d_{2}=500 \mu \mathrm{m}$. (b) SEM image of the cross-section of the zinc-coated steel after rectangular patterning using nanosecond laser irradiation. (c) Magnified image of the cross-section of the zinc-coated steel after rectangular laser patterning. The hum height and the pattern depth are shown in the figure. (d) The SEM images of the zinc-coated steel after each laser scan.

The pattern depth and the hump height are measured w.r.t. the number of scan passes $N_{2}$, and the results are shown in Figure 5a,b. As expected, the pattern depth consistently increases with the increasing $\mathrm{N}_{2}$ value, since more material is removed as the number of scans is increased. The height of the hump was found to generally increase with increasing $P_{2}$ values, but the trend is inconclusive for increasing $\mathrm{N}_{2}$ values due to large variations. Formation of the hump is undesirable, since it hampers tight contact between the materials to be welded, leading to increased gas encapsulation and lower weld qualities.

Tensile shear load test results for the laser fusion-bonded CFRP and pre-inscribed rectangular surface patterned zinc-coated steel is shown in Figure 6a for varying $N_{2}$ values and in Figure $6 \mathbf{b}$ for varying $d_{2}$ values. The results clearly show that the tensile shear load is at maximum for $N_{2}=1$ and decreases as $\mathrm{N}_{2}$ is increased to 3 , and then is approximately maintained at a constant value. The figure also shows that the power of the nanosecond laser used to pattern the zinc-coated steel does not influence the tensile shear strength of the joint. Such results indicate that the pattern depth and the hump height resulting from the pattering laser does not correlate with the tensile shear strength. For example, the presence of the pattern indeed increases the tensile shear strength of the fusion-welded CFRP and zinc-coated steel. However, when the pattern depth becomes more than $75 \mu \mathrm{m}$, it causes an adverse effect. Figure 7 shows the SEM image of the fractured cross-section of the welded joint after the 
tensile shear test. The figure shows that CFRP residues are present within the laser-patterned grooves. This shows that the improved anchoring effect due to the laser pattern causes a partial cohesive fracture resulting in improved joining strength compared to that of the pure interfacial fractures observed in the joint with no patterns. The tensile shear load test results for the laser fusion-bonded CFRP and surface patterned zinc-coated steel are shown in Figure $6 \mathrm{~b}$ for the varying pattern pitch $d_{2}$ when $N_{2}=1$. The results show that for all the pattern pitch sizes, the tensile shear load is increased compared to the samples with no surface pattern. Considering the uncertainty of the results, we conclude that the optimal pattern pitch is near $500 \mu \mathrm{m}$, which results in an approximately $100 \%$ increase in tensile shear load compared to that of no surface patterning, although the correlation between tensile shear load and pitch is marginal.

(a)

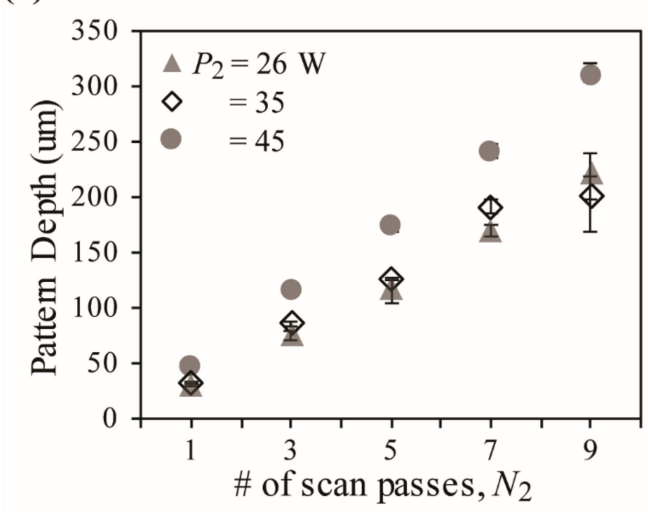

(b)

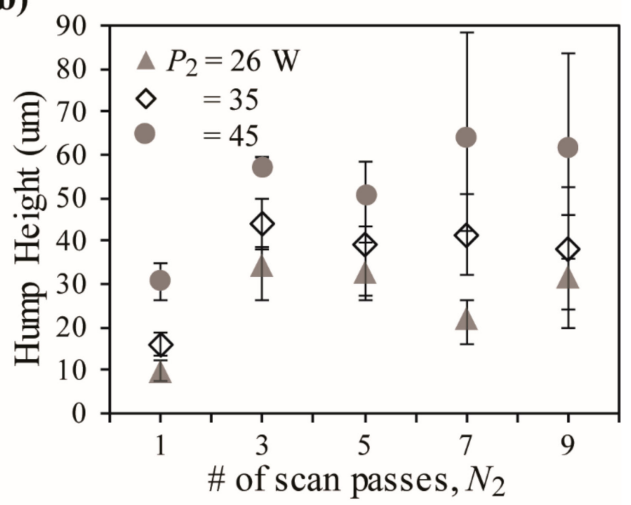

Figure 5. (a) Pattern depth variation and (b) hump height variation w.r.t. the number of scan passes $N_{2}$ under different nanosecond laser powers $P_{2}=26 \mathrm{~W}, 35 \mathrm{~W}$, and $45 \mathrm{~W}$. A laser scan speed of $v_{2}=200 \mathrm{~mm} / \mathrm{s}$ and focal length of $z_{2}=0 \mathrm{~mm}$ were used.

(a)

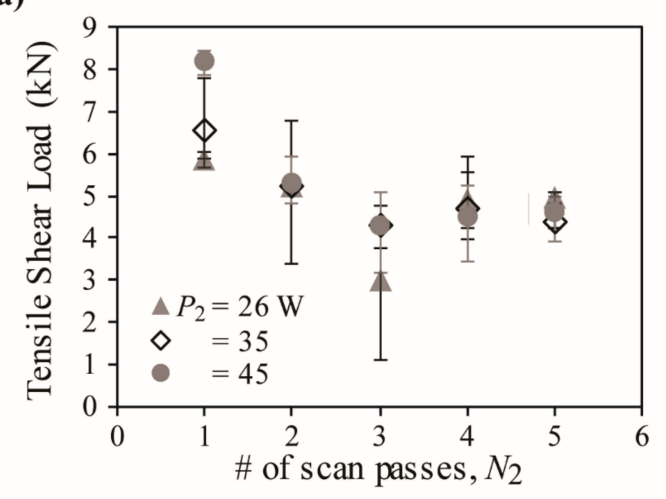

(b)

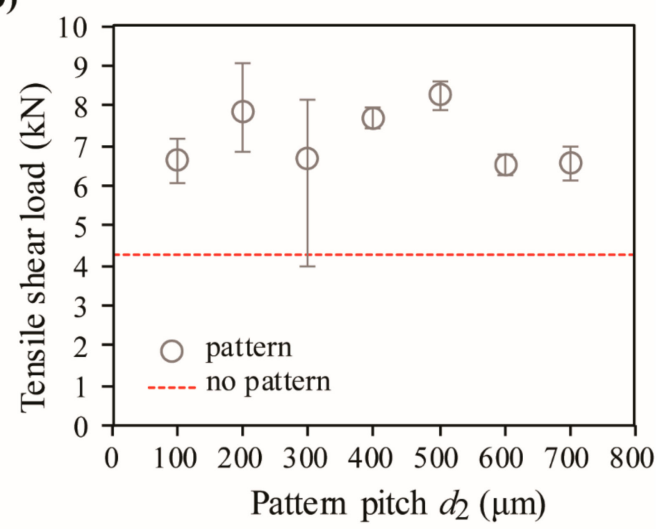

Figure 6. (a) Tensile shear load variation w.r.t. the number of scan passes $N_{2}$ under different laser powers $P_{2}=26 \mathrm{~W}, 35 \mathrm{~W}$, and $45 \mathrm{~W} . d_{2}=500 \mu \mathrm{m}, v_{2}=200 \mathrm{~mm} / \mathrm{s}$, and $z_{2}=0 \mathrm{~mm}$ were used. (b) Tensile shear load variation w.r.t. the pattern pitch $d_{2}$. Laser power $P_{2}=45 \mathrm{~W}, N_{2}=1, v_{2}=200 \mathrm{~mm} / \mathrm{s}$, and $z_{2}=0 \mathrm{~mm}$ were used.

The cross-section of the laser fusion-welded CFRP and zinc-coated steel was investigated using SEM imaging to understand the nature of the increased tensile shear strength up to $N_{2}=3$ and decreased tensile shear strength at $N_{2}=5$. The SEM images in Figure 8 show that at $N_{2}=1$, the PEEK matrix has seeped into the shallow grooves formed by the pre-inscription during the laser fusion process forming a tight bond between the two dissimilar material, thereby increasing the bonding strength. However, as $N_{2}$ is increased to 3 , the images show that the recondensed particles become trapped inside of the pre-inscription, hindering the PEEK matrix from flooding the grooves. As $\mathrm{N}_{2}$ 
is increased further to 5, the images show that some grooves formed by the pre-inscription have become too deep for the PEEK matrix to seep into the cavities during the welding process, leaving large vacancies in which gases may be trapped. Such results show that although all the joints with rectangular patterns result in a higher tensile shear load compared to that of non-patterned joints, there exist optimal parameters that maximize the bonding strength between the CFRP and zinc-coated steel.

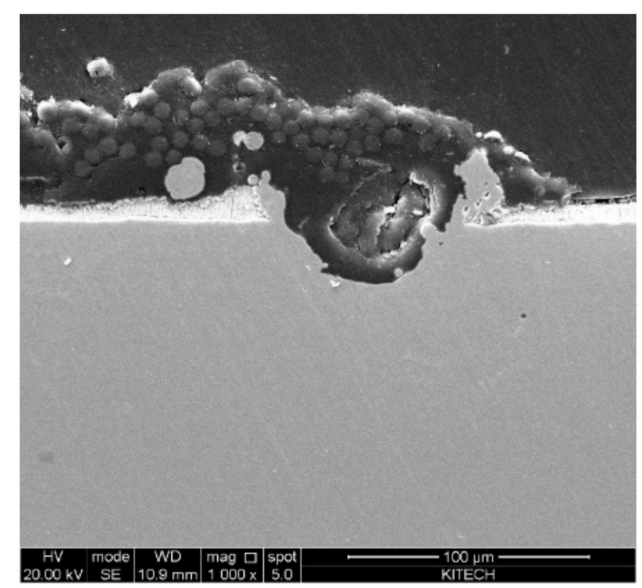

Figure 7. The SEM image of the fractured cross-section for the laser fusion-welded CFRP and zinc-coated steel joint with laser patterned grooves after the tensile shear test.

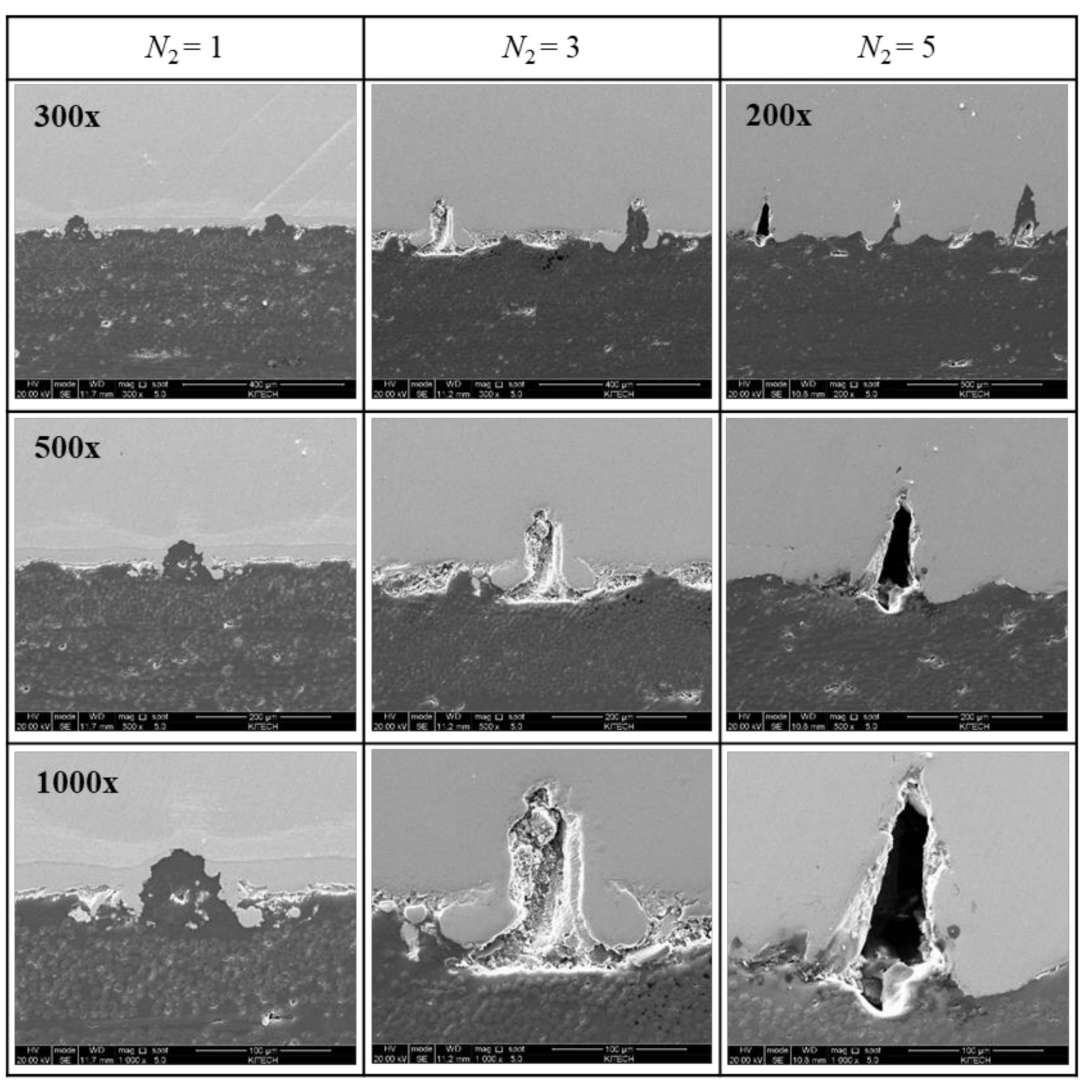

Figure 8. SEM images of the laser fusion cross-section of CFRP and galvanized steel w.r.t. the number of laser scans $N_{2}$ to form the pre-inscribed rectangular patterns. The parameters used for this bonding are: $P_{1}=500 \mathrm{~W}, N_{1}=2, z_{1}=10 \mathrm{~mm}, d_{1}=5 \mathrm{~mm}, P_{c}=5 \mathrm{MPa}, v_{1}=10 \mathrm{~mm} / \mathrm{min}, P_{2}=45 \mathrm{~W}, N_{2}=1$, $v_{2}=200 \mathrm{~mm} / \mathrm{s}$, and $z_{2}=0 \mathrm{~mm}, d_{2}=500 \mathrm{um}$. 
Figure 9 shows the comparison of the tensile shear load test results for the CFRP and zinc-coated steel joint using four different kinds of methods: self-piercing rivet, laser fusion bonding with and without pre-inscribed patterning, and adhesive bonding. The results show that for this study, joints formed using non-patterned laser fusion bonding exhibit comparable tensile shear loads to self-piercing rivets with approximately $4 \mathrm{kN}$, while joints formed using patterned laser fusion bonding exhibit comparable tensile shear loads to adhesive bonding with approximately $8 \mathrm{kN}$. Therefore, it can be concluded that the pre-inscribed rectangular patterns on the zinc-coated steel sheets significantly improve (up to $100 \%$ ) the tensile shear load of joints between CFRP and zinc-coated steel, and this is a result of an improved fusion between the two dissimilar materials due to the presence of pre-inscribed grooves.

(a)

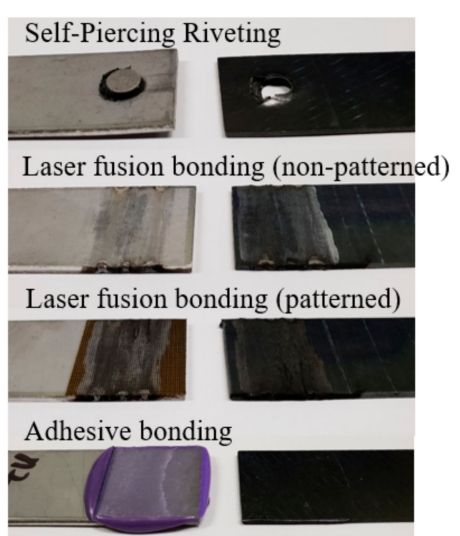

(b)

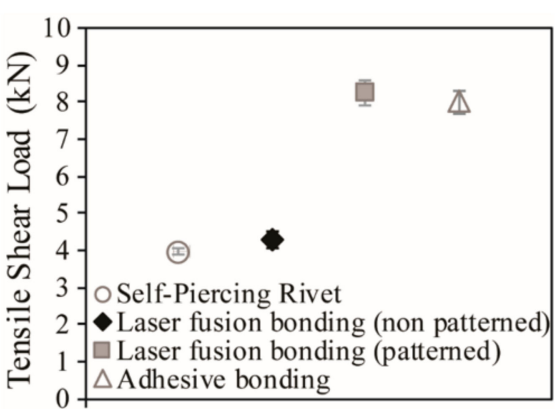

Figure 9. The failure surfaces and the tensile shear load test results of joints between CFRP and zinc-coated steel formed by four different methods: self-piercing rivet, laser fusion bonding with and without the pre-inscribed patterns, and adhesive bonding.

\section{Conclusions}

In this study, we present improved tensile shear load results of bonded CFRP and pre-inscribed patterned galvanized steel. We first carried out a parametric study to optimize the laser processing parameters for joining CFRP and zinc-coated steel for non-patterned cases. Then, using the optimized fusion bonding parameters, we investigated the effect of the pre-inscribed rectangular grid patterns on the surface of zinc-coated steel prior to laser fusion bonding.

The following conclusion can be made from this study:

1. The optimized laser fusion bonding parameters for this study were found to be $P_{1}=0.7 \mathrm{~kW}$, $z_{1}=10 \mathrm{~mm}, d_{1}=3 \mathrm{~mm}, N_{1}=2$, and $P_{\mathrm{c}}=5 \mathrm{MPa}$.

2. The number of scan passes $N_{2}$ during the surface patterning process results in controllable pattern depth but uncontrollable hump height and pattern width.

3. The optimal processing parameters for the pre-inscribed rectangular pattern on the zinc-coated steel were found to be $P_{2}=0.45 \mathrm{~kW}, d_{2}=500 \mu \mathrm{m}$, and $N_{1}=1$.

4. An increased tensile shear load is expected for all the grid pitch sizes with a maximum increase value of $100 \%$ over the sample with no patterns ( $4 \mathrm{kN}$ to $8 \mathrm{kN})$.

5. The increased tensile shear load for joints with the pre-inscribed patterns is the result of the increased bond surface area between the PEEK matrix and the zinc-coated steel.

6. Increasing $N_{2}$ values decrease the tensile shear load of the joints due to an increased amount of recondensed particles and the formation of cavities.

We hope that the results presented in this study advance the efficiency and the effectiveness of joining CFRP and zinc-coated steel, leading to the wide use of CFRP in many areas of engineering. 
Author Contributions: Conceptualization, D.-H.K.; Methodology, N.-K.J. and T.-E.J.; Software, N.-K.J. and T.-E.J.; Validation, N.-K.J. and T.-E.J.; Formal Analysis, D.-H.K.; Investigation, N.-K.J. and T.-E.J.; Resources, D.-H.K.; Data Curation, D.-H.K. and J.K.; Writing-Original Draft Preparation, D.-H.K. and J.K.; Writing-Review and Editing, J.K.; Visualization, N.J. and T.-E.J.; Supervision, D.-H.K.

Funding: This work was supported by the Korea Institute of Industrial Technology and the Ministry of Trade, Industry, and Energy of the Republic of Korea and by the Ministry of Science and ICT (No. 2019M3A6B3032325, 2016R1D1A1B03935743, 2015R1A6A1A03031833).

Conflicts of Interest: The authors declare no conflict of interest.

\section{References}

1. Pramanik, A.; Basak, A.K.; Dong, Y.; Sarker, P.K.; Uddin, M.S.; Littlefair, G.; Dixit, A.R.; Chattopadhyaya, S. Joining of carbon fibre reinforced polymer (CFRP) composites and aluminium alloys-A review. Compos. Part A 2017, 101, 1-29. [CrossRef]

2. Isenstadt, A.; German, J.; Bubna, P.; Wiseman, M.; Venkatakrishnan, U.; Abbasov, L.; Guillen, P.; Moroz, N.; Richman, D.; Kolwich, G. Lightweighting technology development and trends in U.S. passenger vehicles. Int. Counc. Clean Transp. 2016, 25, 1-24.

3. Mascarin, A.; Hannibal, T.; Raghunathan, A.; Ivanic, Z.; Francfort, J. Vehicle Lightweighting: 40\% and 45\% Weight Savings Analysis: Technical Cost Modeling for Vehicle Lightweighting; Idaho National Laboratory: Idaho Falls, ID, USA, 2015; EXT-14-33863.

4. Katayama, S.; Kawahito, Y. Laser direct joining of metal and plastic. Scr. Mater. 2008, 59, 1247-1250. [CrossRef]

5. Jung, K.W.; Kawahito, Y.; Takahashi, M.; Katayama, S. Laser direct joining of carbon fiber reinforced plastic to zinc-coated steel. Mater. Des. 2013, 47, 179-188. [CrossRef]

6. Rauschenberger, J.; Cenigaonaindia, A.; Keseberg, J.; Gubler, U.; Liébana, F. Laser hybrid joining of plastic and metal components for lightweight assemblies. In Proceedings of the Lasers in Manufacturing Conference 2015, Munchen, Germany, 22-25 June 2015.

7. Heckert, A.; Zaeh, M.F. Laser Surface Pre-treatment of Aluminium for Hybrid Joints with Glass Fiber Reinforced Thermoplastics. Phys. Procedia 2014, 56, 1171-1181. [CrossRef]

8. Gabrion, X.; Placet, V.; Trivaudey, F.; Boubakar, L. About the thermomechanical behavior of a carbon fibre reinforced high-temperature thermoplastic composite. Compos. Part B Eng. 2016, 95, 386-394. [CrossRef]

9. Lambiase, F.; Ko, D. Feasibility of mechanical clinching for joining aluminum AA6082-T6 and Carbon Fiber Reinforced Polymer sheets. Mater. Des. 2016, 108, 341-352. [CrossRef]

10. Zhang, Z.; Shan, J.; Tan, X.; Zhang, J. Improvement of the laser joining of CFRP and aluminum via laser pre-treatment. Int. J. Adv. Manu. Technol. 2017, 90, 3465-3472. [CrossRef]

11. Zhang, Z.; Shan, J.; Tan, X. Evaluation of the CFRP grafting and its influence on the laser joining CFRP", to aluminum alloy. J. Adhes. Sci. Technol. 2017, 32, 390-406. [CrossRef]

(C) 2019 by the authors. Licensee MDPI, Basel, Switzerland. This article is an open access article distributed under the terms and conditions of the Creative Commons Attribution (CC BY) license (http://creativecommons.org/licenses/by/4.0/). 